\title{
Article
}

\section{Bridging the Political Deficit: Loss, Morality, and Agency in Films Addressing Climate Change}

\author{
Hammond, Philip and Ortega Breton, Hugh
}

Available at http://clok.uclan.ac.uk/26514/

Hammond, Philip and Ortega Breton, Hugh ORCID: 0000-0001-6777-6522

(2014) Bridging the Political Deficit: Loss, Morality, and Agency in Films Addressing Climate Change. Communication, Culture \& Critique, 7 (3). pp. 303-319. ISSN 1753-9129

It is advisable to refer to the publisher's version if you intend to cite from the work. http://dx.doi.org/10.1111/cccr.12052

For more information about UCLan's research in this area go to http://www.uclan.ac.uk/researchgroups/ and search for < name of research Group>.

For information about Research generally at UCLan please go to http://www.uclan.ac.uk/research/

All outputs in CLoK are protected by Intellectual Property Rights law, including Copyright law. Copyright, IPR and Moral Rights for the works on this site are retained by the individual authors and/or other copyright owners. Terms and conditions for use of this material are defined in the policies page.

\section{CLoK}

Central Lancashire online Knowledge www.clok.uclan.ac.uk

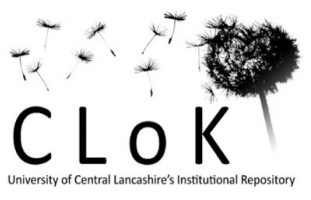




\section{Bridging the Political Deficit: Loss, Morality and Agency in Films Addressing Climate Change}

At the turn of the century fear became a dominant frame in television, press and film entertainment (Altheide 2002) and in politics (Lipschutz 1999), grounded in the cultural and governmental prevalence of risk anxiety or consciousness (Furedi 2005). The apparent potential of fear as a meaningful driver for political and behavioural change has been mobilised by a wide range of pressure groups, including environmentalists, seeking to engage in today's 'post-political' terrain. However, when dealing with future-located risks such as major anthropogenic climate change, the use of fear of catastrophe appears to be ineffective because the severity of predicted dangers does not correlate with everyday knowledge and experience of present circumstances. Perhaps in an attempt to overcome this political deficit, emotional rhetorical strategies have developed towards attempting to create engagements with the problem of climate change using other emotions, such as hope, guilt, compassion and, in particular, nostalgia (Höijer 2010). However, emotions are not simply chosen by producers, directors and writers for their perceived efficacy in communicating a message: in a parallel development, an increase in emotional expression is evident both in politics and a number of media formats which foreground the human as an individual, emotional subject. The relative predominance of some emotions over others in mainstream representations is shaped by directorial decisions in the context of these historical processes and developments in generic conventions.

The films discussed here - The Day After Tomorrow (2004), An Inconvenient Truth (2006) and The Age of Stupid (2009) - do objectify negative risk perceptions and calculations into future, apocalyptic events and scenarios. However, their attempts to provoke political action are based on evocations of loss set in the present and past which as a result have the potential to produce emotional engagements. Whether these identifications then lead to action to combat climate change is not our focus here, although we do assess some reception studies of these films in order to distinguish our approach. Rather, our interest lies in what these films, as cultural artefacts, can tell us about the political culture in which they are produced. Specifically, we are interested in the way personal loss and morality are used as motivation, and the uses made of times and places to represent these meaningfully. What we find most fascinating about these films is that autobiographical narratives of loss and morality occupy the space once dominated by modernist forms of politics. In particular, the use of different temporalities, facilitating feelings of regret, nostalgia, sadness and grief, supports the theory that alongside other developments in political communications, an individuated, 'therapeutic' ethos is now an established framework for political engagement in Anglo-American societies in the current historical period. Our aim is to engage with the specificity of these representations and position them in the context of the fundamental changes to political subjectivity of the last thirty years. The loss of modernist Left- and Right-wing political ideologies at the end of the 1980s provides fertile ground for what has been referred to as 'post-traumatic culture' (Farrell 1998), 'therapeutic culture' 
(Richards 2000) and 'traumaculture' (Luckhurst 2003) to develop, because this emotive subjectfocussed discourse provides a framework for managing individuated anxieties about agency in a social situation characterised by greater uncertainty and a perception of powerlessness. The global scale of anthropogenic climate change, and the focus on future negative consequences, gives expression to both these characteristics.

In all the films discussed here, the experience of personal loss, the potential for future loss, and the emotions associated with loss are fundamental to affective engagement. We claim that underlying the evocation of such emotions is a historical loss of modernist political subjectivity (Heartfield 2002) which has been displaced and given expression through a range of individuated, trauma narratives (Luckhurst 2003; Perri 6 et al. 2007; Brown 1995) and risk-based social problems, including the problem of anthropogenic climate change. In supporting this claim, we seek to move outwards from a consideration of the texts' emotional rhetoric toward what Gill Branston (2007: 225) calls 'the hugely difficult structures of feeling ${ }^{1}$ which environmental awareness often involves'. In the following section we highlight the problems and limitations of effects research, before then going on to develop our own analysis of these films, examining themes of loss and nostalgia, and representations of agency

\section{Mobilising emotions}

A number of authors have emphasised the importance of emotional appeals to the success of environmental campaigns. A 2009 report by the American Psychological Association's Task Force on the Interface Between Psychology and Global Climate Change, for example, notes that 'risk perceptions...are influenced by associative and affect-driven processes as much or more than by analytic processes' (Swim et al. 2009: 37). The implication that emotional appeals are as important, or more important, than information and rational argument has been made explicitly in a number of studies. Anthony Leiserowitz (2006: 63) argues that 'risk perception is greatly influenced by affective and emotional factors', for instance; while Elke Weber (2006: 116) suggests that 'attention-catching and emotionally-engaging informational interventions may be required to engender the public concern necessary for individual or collective action in response to global warming'.

The idea that affect is more important than cognitive reasoning is not a new one. There is a long research tradition in psychology making this point both in general terms and specifically in relation to environmentalism. Julie Ann Pooley and Moira O'Connor, for instance, argued more than a decade ago that 'the key entry point for environmental education is via the affective domain' (Pooley and O'Connor 2000: 712). It may be that this argument - for the importance, even the primacy of emotional reactions over logical thought - continues to be reiterated (often as if it were a new insight) because it chimes with contemporary concerns and assumptions. In relation to environmental campaigning, it offers an explanation for why information campaigns do not appear to be entirely successful in persuading people to 'go green' (Ramesh 2011). More broadly in politics in recent years 
we have seen the rise of the idea of 'nudging' the public to adopt particular ideas or behaviours rather than making an argument that they should do so (Thaler and Sunstein 2008). The notion that political leaders should 'nudge' citizens, or that they should seek to address voters' emotional wellbeing (Richards 2007), perhaps reflects the difficulty that such leaders and other political actors now have in making directly political arguments, given the exhaustion of Left/Right politics since the late 1980s.

Some studies have specifically focussed on the importance of emotional appeals in relation to films about climate change. The most-studied film in this respect is the 2004 Hollywood blockbuster The Day After Tomorrow. A study by Thomas Lowe at the Tyndall Centre for Climate Change Research set out to test the hypothesis that 'a filmic experience, a medium which is specifically designed to manipulate the feelings and emotions of the viewer (and portraying the impacts and implications of climate change in a context or frame which differs significantly from scientific reporting), may promote a greater individual reaction to the potential dangers from climate change' (Lowe 2006: 7). The study found that the film had no significant impact on viewers' ideas about climate change, producing 'very little difference in affect responses' (2006: 38), although other studies have claimed to show that The Day After Tomorrow 'had a significant impact on the climate change risk perceptions, conceptual models, behavioral intentions, policy priorities, and even voting intentions of moviegoers' (Leiserowitz 2004: 34), and that such 'intense dramatizations have real potential to shift public opinion' (Balmford et al. 2004: 1713).

Of course, one might expect a dramatic disaster movie to have some emotional impact, at least in the short term, even if it does not necessarily shift underlying attitudes and behaviours. But two more recent studies have also examined non-fiction environmental films in terms of emotional appeal rather than informational or rational persuasion. Geoffrey Beattie et al. have investigated viewer responses to Al Gore's 2006 documentary An Inconvenient Truth not in terms of the arguments or evidence the film presents, but rather in terms of its affective power. They argue that, since 'much of so-called rational thought is little more than a post-hoc justification for our behaviour', therefore 'we may need something much more concrete and much more emotional to persuade us that global warming is both real and urgent and that we should panic now' (Beattie et al. 2011: 109, 107). Rachel Howell has also recently studied the hybrid drama-documentary The Age of Stupid, taking as her starting point the idea that 'affect - feelings about specific objects, ideas, and images - plays an important part in determining people's attitudes and responses to environmental issues' (Howell 2011: 178).

A problem with these studies of the emotional effects of environmental films is that they pay very little attention to the films themselves. Perhaps because of their disciplinary background (mostly in psychology), these authors attempt virtually no textual analysis; and since they assume that such texts must be making their affective appeals for a 'good cause', there tends to be a rather narrow focus on how successful such appeals are, rather than a more critical reflection on exactly how appeals are made and how human subjectivities are framed. Yet as leading climate scientist Mike Hulme (2009a: 158) argues, it would be 'inexcusable...to pretend that there is just one message, one 
voice, one number to be communicated, that there is just one action agenda that (the science of) climate change demands from us, and that the arts and advertising can deliver it.' Rather than taking the politics of environmentalism as given, it is important to examine how this politics is articulated via the emotional engagements that these films invite. Beattie et al.'s study of the emotional appeals of An Inconvenient Truth, for example, misses the key emotional dynamic of the film despite attempting to identify its most powerful messages. Beattie et al. (2011: 111) identify seven clips from $A n$ Inconvenient Truth 'as being particularly powerful and emotional', though they do not say how these characteristics were determined, nor do they explain what emotions are being evoked. No textual analysis is presented to support this characterisation, and for at least some of the clips it appears distinctly odd. The 'Drowning polar bear' clip, for example, sounds as if it might be emotionally powerful, but is actually a brief and poorly rendered CGI animation showing a polar bear swimming in open ocean looking for ice. ${ }^{2}$ The emotional resonance of such imagery can hardly be assumed. ${ }^{3}$

Beattie et al. also present the clips in a different order from how they appear in the film. It is not clear from their article why they chose to re-order the clips, nor whether the clips were shown to their test subjects in this new order, though it is implied that this was the case. Clips 7, 1 and 6 (in Beattie et al.'s numbering system) closely follow on from one another in the film, for example: there seems to be no obvious reason for either separating or reordering them. In pulling segments of the film out of context and rearranging them in this way, they also disrupt the flow of the film's argument and therefore do not really test the impact of the text as a whole. One example of this is what they label the 'Small planet/the history of the human race' clip: from their description, it appears that they used a clip from near the end of the film featuring an image of the Earth viewed from space. Yet this section picks up a motif from earlier in the documentary - which briefly features in the opening sequence, and then again, more fully, shortly afterwards - so it does not make sense to treat it in isolation. Beattie et al. (2011: 114) classify audience responses to the clips according to a five-point scale, measuring seven mood categories: happiness, sadness, anger, tension, calmness, energy and tiredness. This rather odd pre-selection of possible emotional responses derives from their use (and adaptation) of a pre-existing mood questionnaire. Notably, fear does not feature here, despite the fact that they imply it is a possible response in their description of the clips. It seems likely that Beattie et al. selected what they themselves thought were likely to be 'particularly powerful and emotional' clips and what they thought were important clips - i.e., clips which made significant points or arguments - based on criteria attending only to the substantive, rational issues. Yet this is to ignore what are arguably the most emotional (indeed, emotive) sections of the film.

In fact, as discussed further below, the most obviously 'powerful and emotional' passages of $A n$ Inconvenient Truth bear only tangentially on the substantive issues tackled in the film. Instead, they relate primarily to Gore's nostalgic autobiographical account of his own personal experiences (see further Murray and Heumann 2007). For us, this underlines the importance of a close analysis of the text as a whole for an understanding of these films' affective dynamics and political meanings, in contrast both to the psychology-based studies discussed above, which tend to take the text largely for 
granted, and also to recent developments in 'Media Studies 2.0' in which textual analysis is often dismissed as irrelevant (Gauntlett 2011). The most important features of texts, which give rise to the question of their capability to affect people, are ignored. This is their symbolic structure, which can represent both social and personal fantasies and so provide moments of powerful identification and dis-identification for audiences. Analysing emotional response in isolation also ignores the fact that emotions are relational. Emotions always involve the subjects who express them and the objects and ideas they choose to invest with significance. Our approach places this relationality of emotions, subjectivity and meaning at the centre of the analysis.

We are using a Cultural Studies/Sociology perspective informed by object relations ${ }^{4}$ psychoanalysis (Klein 1975 [1946]; Fairbairn 1952, 1954, 1958; Ogden 1991; Grotstein 1994) combined with a contextualized, semiotic method of textual analysis (Bignell 2009). This provides us with a social and practice-based means for understanding the affective dynamics of identificatory opportunities and the representation of subjectivities and meaningful ideas. Texts are treated as historically specific layered artefacts or repositories of socially mediated cultural processes (Kellner 1995; Rustin and Rustin 2002). Our approach is referred to as psycho-cultural (Bainbridge and Yates 2011; Ortega Breton 2011) to denote that we recognise the inter-connectedness of sociological and psychological processes, and the insufficiency of either of these disciplines adequately to grasp the affective dynamics of representations, particularly when examining the construction of meaning and subjectivity in relation to acting in the world. The presentation of our analysis here focuses on themes which are consistent across the three films, and which involve the use of time as a rhetorical device: the signification of loss and nostalgia for times and places which have been lost; and the use of an imagined future.

A key feature of all these films is their use of contrasting time periods to produce spaces for emotional reflection. This is most obviously foregrounded in The Age of Stupid, where it structures the narrative - someone in the future views events in our present/recent past - but the use of time is important in the other films too. Partly this is simply due to the nature of climate change as a future-located risk: all three films, to a greater or lesser extent, imagine how the present will be viewed from the perspective of a future in which action to address climate change has not been taken. In addition, the films all invoke nostalgia for a lost past, partly from the perspective of the imagined future, but also a present nostalgia for past losses. Nostalgia in representations of the environment has been identified previously (Ingram 2000, Höijer 2010). In his survey of Hollywood environmental films, David Ingram identifies a consistent theme, an 'uneasy combination of nostalgia for a seemingly lost authentic relationship between human beings and non-human nature, before the despoilations of modernity, with a reliance on a technological fix to solve environmental problems' (2000: 180). Ingram's significant critique is that the use of technology as a solution avoids the prior issue of political will. However the consistency of the representation of nostalgia for a lost relationship is also important for understanding the political status of these films. Nostalgia for a prior, preferred relationship often involves a degree of idealisation of that relationship with which the lived present cannot compete. 
Nostalgia for times and situations past are conceived in personal, human-interest terms, often in the form of individuals recounting memories to camera, so that the public, political messages the films attempt to communicate become intertwined with personal sadness, longing and moral judgements about the present. Moreover, in imagining a future from which to view the present, these films invite us to make judgements about the worth of contemporary human civilisation, in contrast to an idealised past, and to imagine a negative future as the logical outcome of present trends. The ostensible political 'message' is the necessity for change in the present, but the films' negative, dystopian vision works against this since, as we shall see, it tends to undercut any potential for political agency.

\section{Loss and nostalgia}

The importance of time is foregrounded at the beginning of The Age of Stupid by a fast-motion representation of the natural history of Earth and the social history of humanity. This ends with an image of a flooded central London, followed by a snowless mountain landscape, Las Vegas enveloped by the desert, Sydney burning, a ruined Taj Mahal and a settlement of makeshift buildings with human silhouettes moving slowly against a cloudy and colourless landscape. What has been lost is shown emphatically through the visual representation of iconic cultural locations in ruins and the colourless human settlement. We then hear the voice of The Archivist, indirectly addressing the audience through narration as we first view the isolation and then the content of the Global Archive. His voice is grave, forlorn and mournful as he tells us what the Global Archive is and that 'we could have saved ourselves'. So the film is set in a future in which our civilisation is lost. This status of the audience is materialised in the main viewpoint of The Archivist, viewed from behind the touch-screen of the computer he uses to access, playback and edit the documentary he is making. Like the footage he reviews on-screen, the status of the audience is of an object stored in the machine. The Global Archive, located in an iceless Arctic Sea in 2055, signifies all that has been lost (human civilisation as we know it), since it contains what has been salvaged from a global environmental catastrophe: the representations of human knowledge (servers and their scientific and media contents) and creativity (sculptures and other artworks). The concentration of objects in this multi-level storeroom in the Arctic (a place already associated with environmental loss) indicates that the places that gave them meaning have been lost. The mood is set in this scene by a mid-close up of The Archivist's serious expression, emphasised by the interface of the touchscreen framing his face, and a pause in which he holds his breath and then breathes out deeply, before beginning to use the computer. This suggests the contemplation of a sad or regretful idea. Before we see the first piece of documentary footage he smiles ruefully and asks: 'What state of mind were we in [pause] to face extinction [pause] and simply shrug it off?' This incredulity at society's indifference to catastrophic change is communicated with sadness and regret though facial expressions. Loss is therefore signified in a number of different audio-visual ways, from places as settings of now absent human activity, the absence of colour, scenes of destruction, the absence of ice, narration (the absence of embodied voice), monologue to a 
screen (the absence of an embodied listener) and lastly, but perhaps most effectively, through the close filming of facial expressions of sadness.

In what follows, a range of documentary footage is used to represent personal stories of loss from a selection of people based in different parts of the world. With the exception of Jeh Wadia, a young Indian entrepreneur, the other main characters in The Age of Stupid are represented as individuals who have lost something significant: Fernand - the loss of the local glacier; Jamila and Adnan - the loss of their home and father; Piers Guys - defeated in his proposal for a wind farm; Layefa - the loss of a village, a clean river and a livelihood; $\mathrm{Al}(\mathrm{vin})$ - the loss of his home and all his possessions. These are all losses of meaningful objects imbued with personal meaning. Through the use of music in particular, Jeh and his project are portrayed somewhat comically and dismissively as being focussed solely on gain (of a share of the low-cost budget airline market). His inclusion provides a contrast to the other main characters' stories of loss. Situating these stories in the past, accessed via the characters' storytelling, makes them events which are inaccessible to change. This is emphasised by the film's temporal setting in 2055 displaying peoples' lives from the years 2005-08. Locating recent-present-day characters in the past of a present (2055) where catastrophic events causing global losses have already occurred compounds the sense of loss, futility and hopelessness that these sad stories evoke.

Loss expressed as a sense of nostalgia for a past seen as preferable to the present is evident in the commentary and stories provided by Fernand, Jamila and Adnan, and The Archivist. The melting of the local glacier is represented as a significant loss in the life of mountain guide Fernand, for instance. This loss is emphatically apparent visually, the grooves it once cut into the rock clearly visible (as are his wet eyes and tears when filmed in close-up). Beyond this literal, visual representation of loss (of frozen water - a natural reservoir, and of the tears that descend down his face), what does the glacier stand in for? The answer perhaps comes from the way in which Fernand connects his life to the life of the glacier: it has been a constant presence and as he nears the end of his life, it seems as if the glacier will also no longer exist. The glacier, as a significant object for Fernand, objectifies the passing of life, both natural and human, that is the central concern of The Age of Stupid. By representing these and other stark examples of climate change as human loss (most notably the destruction of parts of New Orleans by Hurricane Katrina) climate change is brought into a human-interest frame that is more meaningful than the majority of science-based reports on the state of the planet because, firstly, it engages with universal, primary and fundamental fantasies and experiences of attachment and loss shared by humans by virtue of our group-based social organisation, and secondly, because of our projection of meaning onto places with which we are familiar and/or which are the settings of meaningful relationships.

Much of the drama in The Day After Tomorrow is also a human one, centred around feelings of hope and loss: there are scenes of human courage, particularly on the part of the emergency services (with echoes of 9/11), and the consequences of climate catastrophe are depicted as an entirely human 
tragedy (for example, the plucky British scientists stoically accepting their inevitable deaths) rather than, say, dwelling on suffering animals. Indeed the film conforms to the disaster-movie genre in the implied 'back-story' of the main characters, who make good past losses in the course of the narrative. In particular, as the protagonist (climate scientist Jack Hall,) battles extreme climate conditions he also works to repair broken family bonds - eventually reuniting with his withdrawn teenage son and estranged ex-wife - so restoring lost personal relationships as the Earth's climatic balance is restored at the end of the film. This human-interest focus is, of course, not surprising in a mainstream Hollywood drama. Yet a very similar approach is evident in Gore's documentary An Inconvenient Truth, which if anything forms an even closer association between climate change and human stories of personal loss.

As noted above, the most emotionally-charged sections of An Inconvenient Truth bear only indirectly on the issue at hand, and instead concern Gore's account of his political and, especially, personal losses. One such sequence is about the time when Gore's son was hit by a car, a near-tragedy which he says had the effect of making him re-prioritise the issue of climate change. Similarly, there is a sequence telling the story of Gore's sister, Nancy, who died of lung cancer, prompting his father to give up farming tobacco. This relates only obliquely to the main issue (the point being that people are sometimes slow to make changes even when faced with evidence), but is highly emotive, not only because of the subject matter of family bereavement but also because of other aspects of the audiovisual presentation. This portion of the film is illustrated with black-and-white family photographs, black-and-white documentary footage of a young woman engaged in cigarette production, and film of Gore revisiting the family farm, with some of the latter sequence having been made to appear as if it is old home-movie footage shot with a cine-camera. This de-colouration emphasises pastness and distinction from the present. These images are complemented by Gore's softly-spoken voiceover and gentle background music.

The visual evocation of Gore's childhood memories here recalls a similar sequence earlier in the film in which his reminiscences about a childhood spent partly on his father's farm are illustrated with old newspaper cuttings, and again with black-and-white family photographs and cine-camera-style footage. This earlier sequence, in turn, also repeats, in a different form, the opening shots of the film, which feature footage of a riverbank (presumably located at or near the farm) to accompany Gore's voiceover:

You look at that river, gently rolling by. You notice the leaves rustling in the wind. You hear the birds, you hear the tree frogs. In the distance you hear a cow. You feel the grass; the mud gives a little bit on the riverbank. It's quiet, peaceful. And all of a sudden, it's a gear shift inside you. And it's like taking a deep breath and going [sigh], 'oh yeah, I forgot about this'.

Gore is establishing a relationship between an external, idealised, and natural environment and personal change and remembrance. This evocative opening is later recalled visually in a photo of the 
family boating on the river, and in the repetition of the riverbank footage, now with the cine-camera effect added. Taken together, the overriding effect of these sections of the film is to evoke a powerful sense of nostalgia. This is nostalgia for his own childhood as a time of harmony and closeness with nature, but it becomes interconnected, via the personal stories of (near) loss of family members, with a sense of grief. Like other aspects of the film this helps to authenticate and personalise the argument and so lend it credibility within an individuated culture (Gore also mentions his personal acquaintance with key figures in science and politics, for example, and his record of involvement with the issue).

Yet this is not simply a personal argument but also, ostensibly, a public, political one. Gore's loss is also political: he introduces himself with a jokey reference to his loss of the 2000 US presidential election, and as he tells the story of his involvement with the issue of climate change he periodically reflects on the disappointments and reversals he has suffered along the way. Personal and public loss thereby become intertwined: the story about his son follows on from some comments about his political efforts and setbacks, and links forward to a sequence which follows soon after on extreme weather events (including Hurricane Katrina), so that Gore's personal misfortunes are connected to a sense of wider tragedy. The nostalgic veneration of what is lost and in the past is thereby connected to a problematic present. Through the interweaving of political and personal narratives, Gore re-poses the issue of climate change as a personal moral choice, stating, for example, that: '[there is a] moral imperative to make big changes'; that 'Ultimately, this is really not a political issue so much as a moral issue'; that allowing a rise in $\mathrm{CO} 2$ emissions would be 'deeply unethical'; and that 'I believe this is a moral issue'. The public disclosure of the difficult experience of loss is the emotional warrant for the claim that climate change is a moral issue (because loss is painful and therefore wrong). The suggestion is that the painful effects of climate change can be avoided through reparative actions which will minimise its impact. Similarly, as with the stories of loss featured in The Age of Stupid there is also the implication that action to halt climate change will in some way mitigate against the losses of the past. There is a further rationale for adopting this position, as Amanda Rohloff argues:

Such a reframing of global warming may assist in overcoming public uncertainty about the danger posed by global warming, by asserting that it is a certain moral issue, thus providing an absolute yes answer to questions of the (moral) danger of this problem....And so global warming becomes not an uncertain risk, but a moral certainty.

(Rohloff 2011: 640)

Despite the danger of climate change posed here, in the context of an everyday life of uncertainties the film provides desirable, anxiety-diminishing certainties. This certainty, however, is based on a particular, emotional orientation to loss. Loss is seen as negative or wrong because of the painful emotions which are associated with it. It is the desire to avoid future loss and pain, the belief that these aspects of life are wrong, which creates this moral certainty. On one level, then, An Inconvenient Truth makes a political argument, offering scientific and documentary evidence in support; but in terms of its emotional appeals - connected much more to a sense of personal 
nostalgia and loss than to the subject-matter of climate change - the film presents a personal, moral argument. It is not so much that emotional or moral appeals are simply added on in order to bolster a political message, but rather that the latter is replaced by the former.

In all three films, climate change is pulled into an affective human-interest frame via association with personal loss. The Age of Stupid envisages a future in which all is lost, and positive change is no longer possible; The Day After Tomorrow and An Inconvenient Truth offer an ostensibly more hopeful vision, but one that is couched in terms of therapeutic personal moral resolution through reparative actions (the mending of broken relationships) or moral certainty (learning from past personal losses). As this suggests, in all three films the question of political agency in the present is implicitly rendered problematic. In its place is interpersonal relatedness at the level of family and community.

\section{Formations of history and the future}

Gore argues that political change is possible, given the 'will', and that technological solutions to the problem are at hand. In this respect An Inconvenient Truth is quite different from The Age of Stupid, which takes a more nihilistic stance. Both films, though, can be understood as concerned with restoring a sense of political purpose or 'mission' (the term Gore uses); and both do so by imagining the judgement of the future on the present (Gore's closing point is that: 'Future generations may well have occasion to ask themselves "what were our parents thinking; why didn't they wake up when they had a chance?"'). The problem of cohering a political constituency in the present is 'resolved', as it were, by speaking on behalf of future generations. In much the same way that former UK prime minister Tony Blair argued that he had to listen to his conscience about the threat of Iraqi 'weapons of mass destruction' (WMD) and that history would be his judge, so Gore argues for a reduction in carbon emissions in terms of 'doing the right thing' and being held to account by posterity. The parallel may seem a surprising one, but it is suggested by Hulme (2006), who has warned against 'invoking catastrophe and chaos as unguided weapons with which forlornly to threaten society into behavioural change', explicitly comparing such alarmism with the scaremongering over Iraq's WMD. The effective idea in each case is a major change experienced as loss set in the future. This is characteristic of the risk society dispositif, which attempts to pre-empt and so prevent incalculable risks which may or may not occur. To support this, the representation of human history tends to be negative.

The representation of social history is important because it provides the context for future political agency. As our previous examples show, history is represented as personal and characterised primarily by a sense of loss. In The Politics of Climate Change (2009: 228) Anthony Giddens argues that 'Doomsday is no longer a religious concept, a day of spiritual reckoning but a possibility imminent in our society and economy.' Yet it appears that imagining an ecological 'doomsday' does involve, if not a traditionally religious dimension, then a reappraisal of values and a kind of political reckoning. 
What is retained from the previous religious narrative is the relationship between knowledge (the revelation or prophecy to the few) and the catastrophic event (the apocalypse).

While appeals on behalf of posterity are oriented toward the future, in the risk society a vision of progress becomes difficult to sustain since, as Ulrich Beck puts it, 'one is no longer concerned with attaining something "good", but rather with preventing the worst' (1992: 49, original emphasis). The vision is dystopian rather than progressive. The Day After Tomorrow and The Age of Stupid are centrally concerned, of course, with imagining dystopia, in the form of a near future devastated by catastrophic climate change. Both films explicitly raise the question of progress, asking what is worth preserving from human civilisation. The Archivist character in The Age of Stupid has salvaged and collected artefacts, though he says nothing about them: the message he beams into space at the end of the film is a warning (the revelation) about humanity's destructive folly rather than a summation of its achievements. According to The Archivist, progress means 'leav[ing] the planet - our families and our communities - in a better state than we found them in'. In this representation progress is restricted to the level of interpersonal relationships; a particularist and conservative position. Elsewhere in the film there is little conception of historical progress. Animated sequences offer simplified, negative, potted histories of war and politics, but these are either understood ahistorically (war as eternal recurrence but with increasingly sophisticated and destructive technology) or as having ended (a series of -isms finishing with consumerism). We are left with a bleak vision of ignorant, 'stupid' humanity being punished and annihilated.

In The Day After Tomorrow, the equivalent of the Global Archive is the New York City Public Library, where the hero's son leads a band of survivors sheltering from the new Ice Age, who are forced to burn books in order to survive. One character hesitates, saving an original Gutenberg bible, and argues with another over which are the most important books to preserve (they happily burn books on now-irrelevant tax laws). The book-burning is not only necessary in order to survive: it is one of a number of reversals and social re-orderings which point up how people's priorities have become skewed - other examples include the coming together of the rich kid and the tramp in the library, breaking down social hierarchy; and the near-fatal fall through the snow-covered glass roof of a shopping mall, re-framing consumer culture as life threatening. In this film too the science confronts the stupid: in the first half of the film, the main drama revolves around the climate-scientist protagonist trying and failing to persuade others to listen - specifically the climate-sceptic Vice President. We see our hero confronting the VP at a UN climate conference at the beginning of the film, and then later telling him that he ignored the science when he could have done something ('You didn't want to hear about the science when it would have made a difference'). They don't listen, and disaster follows. The hero's son - with the benefit of inside information from his father on how to survive the storm - is also ignored by most of his fellow refugees sheltering in the library, who are subsequently found frozen to death. Though it involves a human drama, the fantasy is not one of positive progress or agency, but of survival and recognition of the importance of family relationships. In our closing section we consider the way in which the agency of the environment is represented in relation to human agency. 


\section{Conclusion: nature as active agent of change}

What we do with nature when we use it as a symbol can tell us about the state of our political culture. As a liberal fantasy from the deepest winter of the George W. Bush administration, The Day After Tomorrow shows the effect of climate catastrophe as positive: an overturning of current social hierarchies and priorities. The Vice President (who, as several reviewers pointed out, bears a more than passing resemblance to Dick Cheney) is not only forced to admit the error of his ways (that American society was wrong to think it could use nature's resources without consequences), but there is a wider humbling of American power, for example in the reversed border flow from the USA to Mexico - the image of the US Embassy compound there also recalling America's ignominious flight from Saigon. The global North is brought to its knees, the South implicitly valorised as not part of the problem. Nature intervenes to re-balance and re-order the human world at the same time as reordering the ecosystem (the closing shot is of a pristine Earth seen from space, looking like new). There is also an implied view of nature as in some sense intelligent or wise - the planet repairs itself by purging the pollution; the birds and zoo animals are the first to sense the impending catastrophe. The idea that an outside agency (nature or 'the science') will force people to respond seems to be a recurring fantasy. In The Age of Stupid the imagined effects of climate change on iconic places representing our civilisation as well as the re-presentation of selected news footage showing the destruction caused by adverse weather conditions shows the viewer the power or agency of nature; while Gore's presentation of statistics and projections is designed to emphasise the imperative for people to respond to the Truth, however inconvenient.

Although these films are focussed on the specific issue of climate change, the emotional engagements they offer bring wider cultural anxieties into play, much in the way that the issue of climate change itself acts as a magnet for other problems (Hulme 2009b: 333). In particular, the emotional loading of representations of environmental problems derives partly from concerns about human political agency and subjectivity: the overtly political narratives of these texts attempt to work through the tension between a view of the human subject as both the main cause of environmental problems and the potential redemptive agent who can save the planet (for example by making individual behavioural changes to reduce carbon emissions). The results are contradictory. On the one hand, environmental risk takes on the active role in pushing forward a process of political change, and the narrative tends to be one of hope and renewal. On the other hand, there is often a fascination with destruction and annihilation, in which political engagement is implicitly rejected or seen to fail. In the process, the ostensibly political arguments that these films attempt to make tend in practice to slip instead into moral arguments, emotional pleas, and the assertion of moral certainties, whilst 'agency', through its partial objectification in nature, becomes an uncontrollable destructive capacity which is not a part of human subjectivity, but of an anthropomorphised nature, through images and stories of environmental destruction. The negative portrayals of human history as primarily destructive suggest 
a rejection of the negative aspects of human agency which are instead then projected onto 'nature'. Once outside of human agents, this agency becomes uncontrollable and therefore poses a great threat to survival. In juxtaposition to this, human protagonists are represented as reactive agents of prevention and reparation, seeking to preserve and protect what is considered good in their immediate environment (their families, their communities).

Projecting agency onto nature not only re-presents human agency in an alienated and diminished form, it is also politically counter-productive, because natural change is represented (through the use of space and camera angles) on a vastly larger scale than historical, human actions; a scale that human actions cannot, currently, match. Each film features actions which impact on individual families and interpersonal relationships within immediate, geographical communities. These two extremes of action sustain each other: the representation of large-scale societal change by natural forces encourages the adoption of individuated responses to social problems. This interpretive framework reinforces the individuated orientation of social action. Whilst this activity is idealised as reparative, large-scale changes are portrayed as destructive. In relation to this view of change, human agency is reduced to a solely reactive, non-political, survival and reparative capacity.

If we are projecting our human agency into the natural environment, our ability to understand and to act is reduced, for the time being. However, we cannot foreclose the possibility that as historical beings we may be incubating our large-scale political agency in 'mother' nature, until such time that we can take full responsibility for its ambivalent, destructive as well as creative potential.

\section{Notes}

${ }^{1}$ Raymond Williams's (1977) notion of the 'structure of feeling' was one of the first attempts to conceptualise emotions as something distinct from ideology or 'world view' in Cultural Studies. This is not a structure in a static, supportive sense but the emergence of a coherent form to 'thought as felt and feeling as thought' that is discernible in the forms and conventions of signifiers in representation. It also refers to 'meanings and values as they are actively lived and felt' (Williams 1977: 132). These films show the values of climate change action in this way. Williams emphasises that rather than being something beneath the surface, structures of feeling are 'practical consciousness of a present kind' (1977: 132). This concept has subsequently been used in quite a different way from its original conception: 'operating largely beneath the surface, "structures of feeling" refers to the particular emotional tone of a historical period or epoch such as the pervasiveness of anxiety in late modernity' (Clarke, Hoggett and Thompson 2006: 163). This refers to structure in a conventional sense. The two distinct levels are not mutually exclusive and may in fact be mutually supportive in the social reproduction of risk consciousness. This concept is useful for understanding the connected historical, affective and social dimensions of representations of political agency in relation to climate change. 
${ }^{2}$ It is worth noting that this was one of the 'nine factual errors' found in the 2007 UK High Court ruling on plans to show the film in schools. Contrary to Gore's claim that a scientific study had for the first time shown polar bears drowning because of having to swim long distances (up to 60 miles) to find ice, the judge in the case said that 'The only scientific study that either side before me can find is one which indicates that four polar bears have recently been found drowned because of a storm' (BBC 2007).

${ }^{3}$ As Hulme notes, 'the iconography of the polar bear as signifier of climate change may as easily be seen as a site of heightened controversy and disagreement than as one that effectively stabilises debate and concern around a shared natural "treasure".' The imagery might have a powerful emotional appeal for some, but 'has little or no traction among those who are not interested in polar bears' (Hulme 2009b: 242).

4 'Object relations' refers to significant experiences and fantasies as mental objects (the 'object' is anything which has meaning, and therefore an emotional connotation), which because of their significance become a fundamental part of perceptive and communicative processes. Also see Richards (1994:170, n3).

\section{References}

Altheide, David L. (2002) Creating Fear: News and the Construction of Crisis. New York, NY: Aldine de Gruyter.

Bainbridge, Caroline and Candida Yates (2011) 'Therapy Culture / Culture as Therapy: Psychocultural Studies of Media and the Inner World', Free Associations: Psychoanalysis and Culture, Media, Groups, Politics, 62 (September): i-v.

Balmford, Andrew, Andrea Manica, Lesley Airey, Linda Birkin, Amy Oliver and Judith Schleicher (2004) 'Hollywood, climate change, and the public' (Letter), Science, 305: 1713.

BBC (2007) 'Gore climate film's nine "errors"', BBC News, 11 October, http://news.bbc.co.uk/1/hi/7037671.stm, accessed 10 May 2012.

Beattie, Geoffrey, Laura Sale and Laura McGuire (2011) 'An inconvenient truth? Can a film really affect psychological mood and our explicit attitudes towards climate change?', Semiotica, 187 (October): 105-25.

Beck, Ulrich (1992) Risk Society: Towards a New Modernity. London: Sage. 
Bignell, Jonathan (2009) 'The Police Series', in John Gibbs and Douglas Pye (eds.), Close-Up 03. London: Wallflower Press, pp.1-66.

Branston, Gill (2007) 'The Planet at the End of the World: "Event" Cinema and the Representability of Climate Change', New Review of Film and Television Studies, 5 (2): 211-29.

Brown, Wendy (1995) States of Injury: Power and Freedom in Late Modernity. Princeton, NJ: Princeton University Press.

Clarke, Simon, Paul Hoggett and Simon Thompson (2006) 'Moving Forward in the Study of Emotions: Some Conclusions', in Simon Clarke, Paul Hoggett and Simon Thompson (eds.) Emotion, Politics and Society. London: Palgrave Macmillan, pp. 162-175.

Fairbairn, W.R.D. (1952) Psychoanalytic Studies of Personality. London: Tavistock.

Fairbairn, W.R.D. (1954) 'Observations on the nature of hysterical states', British Journal of Medical Psychology, 27: 105-25.

Fairbairn, W.R.D. (1958) 'On the nature and aims of psychoanalytic treatment', International Journal of Psychoanalysis, 39: 374-85.

Farrell, Kirby (1998) Post-Traumatic Culture: Injury and Interpretation in the Nineties. Baltimore, MD: John Hopkins University Press.

Furedi, Frank (2005) Culture of Fear: Risk Taking and the Morality of Low Expectations (Revised Edition). London: Continuum.

Gauntlett, David (2011) Media Studies 2.0, and other battles around the future of media research [Kindle e-book, via www.amazon.co.uk].

Giddens, Anthony (2009) The Politics of Climate Change. Cambridge: Polity.

Grotstein, James S. (1994) 'Projective Identification and Counter-Transference: A Brief Commentary on Their Relationship', Contemporary Psychoanalysis, 30: 578-92.

Heartfield, James (2002) The 'Death of the Subject' Explained. Sheffield: Sheffield Hallam University Press. 
Höijer, Birgitta (2010) 'Emotional anchoring and objectification in the media reporting on climate change', Public Understanding of Science, 19 (6): 717-31.

Howell, Rachel A. (2011) 'Lights, camera ... action? Altered attitudes and behaviour in response to the climate change film The Age of Stupid', Global Environmental Change, 21: 177-87.

Hulme, Mike (2006) 'Chaotic World of Climate Truth', BBC, 4 November, http://news.bbc.co.uk/1/hi/6115644.stm, accessed 10 May 2012.

Hulme, Mike (2009a) 'Many types of action are required to tackle climate change' (Letter), Nature, 462 (12 November): 158.

Hulme, Mike (2009b) Why We Disagree About Climate Change. Cambridge: Cambridge University Press.

Ingram, David (2000) Green Screen: Environmentalism and Hollywood Cinema. Exeter: University of Exeter Press.

Kellner, Douglas (1995) Media Culture: Cultural Studies, Identity and Politics Between the Modern and the Postmodern. London: Routledge.

Klein, Melanie (1975 [1946]) Envy and Gratitude and Other Works 1946-1963. London: The Hogarth Press.

Leiserowitz, Anthony (2004) 'Before and after The Day After Tomorrow: a U.S. study of climate change risk perception', Environment, 46 (9): 22-37.

Leiserowitz, Anthony (2006) 'Climate change risk perception and policy preferences: the role of affect, imagery, and values', Climatic Change, 77 (1): 45-72.

Lipschutz, Ronnie D. (1999) 'Terror in the Suites: Narratives of Fear and the Political Economy of Danger', Global Society, 13 (4): 411-39.

Lowe, Thomas (2006) Vicarious experience vs. scientific information in climate change risk perception and behaviour: a case study of undergraduate students in Norwich (Technical Report 43). Norwich: Tyndall Centre for Climate Change Research, www.tyndall.ac.uk/sites/default/files/t3_32a.pdf, accessed 10 May 2012.

Luckhurst, Roger (2003) 'Traumaculture', New Formations, 50: 28-47. 
Murray, Robin and Joseph Heumann (2007) 'Al Gore's An Inconvenient Truth and its skeptics: a case of environmental nostalgia', Jump Cut, 49, www.ejumpcut.org/archive/jc49.2007/inconvenTruth/, accessed 10 May 2012.

Ogden, Thomas H. (1991) 'Analyzing the Matrix of Transference', International Journal of PsychoAnalysis, 72: 593-605.

Ortega Breton, Hugh (2011) 'Coping with a crisis of Meaning: Televised Paranoia', Free Associations: Psychoanalysis and Culture, Media, Groups, Politics, 62 (September): 85-110.

Perri 6, Susannah Radstone, Corinne Squire and Amal Treacher, eds. (2007) Public Emotions. London: Palgrave Macmillan.

Pooley, Julie Ann and Moira O'Connor (2000) 'Environmental Education and Attitudes: Emotions and Beliefs are What is Needed', Environment and Behavior, 32 (5): 711-23.

Ramesh, Randeep (2011) 'Public support for tackling climate change declines dramatically', Guardian, 7 December, www.guardian.co.uk/environment/2011/dec/07/public-support-climate-change-declines, accessed 10 May 2012.

Richards, Barry (1994) Disciplines of Delight: The Psychoanalysis of Popular Culture. London: Free Association Books.

Richards, Barry (2000) 'The Real Meaning of Spin: Containment and Compression in Modern Politics', Soundings, 14 (Spring): 161-70.

Richards, Barry (2007) Emotional Governance. Basingstoke: Palgrave Macmillan.

Rustin, Margaret and Michael Rustin, M. (2002) Mirror to Nature: Drama, Psychoanalysis and Society. London: Karnac Books.

Swim, Janet, Susan Clayton, Thomas Doherty, Robert Gifford, George Howard, Joseph Reser, Paul Stern and Elke Weber (2009) Psychology and Global Climate Change: Addressing a Multi-faceted Phenomenon and Set of Challenges. Report by the American Psychological Association's Task Force on the Interface Between Psychology and Global Climate Change. Washington, DC: American Psychological Association, www.apa.org/science/about/publications/climate-change.pdf, accessed 10 May 2012. 
Thaler, Richard H. and Cass R. Sunstein (2008) Nudge: Improving Decisions About Health, Wealth and Happiness. New Haven, CT: Yale University Press.

Weber, Elke U. (2006) 'Experience-Based and Description-Based Perceptions of Long-Term Risk: Why Global Warming Does Not Scare Us (Yet)', Climatic Change, 77: 103-20.

Williams, Raymond (1977) Marxism and Literature. Oxford: Oxford University Press. 